\title{
Using debitage analysis to investigate an Alberta archaeological site
}

\author{
by Jennifer Hallson
}

\begin{abstract}
Ahai Mneh (FiPp-33) is a significant pre-contact archaeological site in Alberta. Located west of Edmonton on Lake Wabamun, this site contains material from the Early Prehistoric right up until Late Prehistoric pre-contact times. Ninety-five percent of the lithic artifacts collected are pieces of debitage. Aggregate analysis is a method of examining the whole of the debitage collection, rather than analysing singular pieces. This method is more time efficient, less subject to bias, replicable, and is used often, and successfully, at archaeological sites with immense quantities of debitage. Here I use aggregate analysis to examine the debitage assemblage from two field schools at Ahai Mneh. I investigate various characteristics such as size, raw material type, cortex amount, and number of dorsal scars. I argue that this method is successful, as it provided new information on where people were acquiring raw materials, as well as what types of flintknapping occurred at this site. These analyses resulted in the determination of a focus on local raw material, yet this material was being brought to the site as prepared cores or blanks, rather than complete unaltered cores. Tool production was the focus at this site, and this trend continued throughout time.
\end{abstract}

\section{Introduction}

Ahai Mneh (FiPp-33) is a significant archaeological site in Alberta that has produced material from the Early Prehistoric Period through to the Late Prehistoric Period. It is located south of Lake Wabamun and west of the city of Edmonton (fig. 1). Cultural Resource Management (CRM) work at this site has determined that it is a multicomponent precontact campsite (Soucey et al. 2009). Two field schools run by the Institute of Prairie Archaeology (IPA) at the University of Alberta in 2010 and 2012 support this determination. The majority of the artifacts found were pieces of lithic debitage: the detached pieces of stone created during the manufacture of stone tools (also known as flakes, debris, chips, or refuse). I performed aggregate analysis on the debitage collected during these field schools to identify

Jennifer Hallson completed her MA in the Department of Anthropology at the University of Alberta (previous affiliation [hallson@ualberta.ca]). and classify the debitage to further inform the overall site interpretation. Aggregate analysis is a method that groups debitage within an assemblage based on non-technological criteria (Larson 2004:6); i.e., not identifying the tool (technology) that was being produced. I argue that this method is successful at indicating activities and behaviour that occurred at the site with respect to lithic technology and argue that this method should be used at other sites where there are large amounts of debitage.

\section{Previous Research at Ahai Mneh}

Previous excavations and analysis at Ahai Mneh identify this site as a multi-component campsite where various activities (hunting, hide-working, etc.) occurred over a ca. 10000 year span (Rawluk et al. 2011; Schenk and Yanicki 2011; Soucey et al. 2009). Ahai Mneh covers an area around $10000 \mathrm{~m}^{2}$ and contains projectile points from throughout the precontact period (Table 1). Occupation appears to have begun during the 


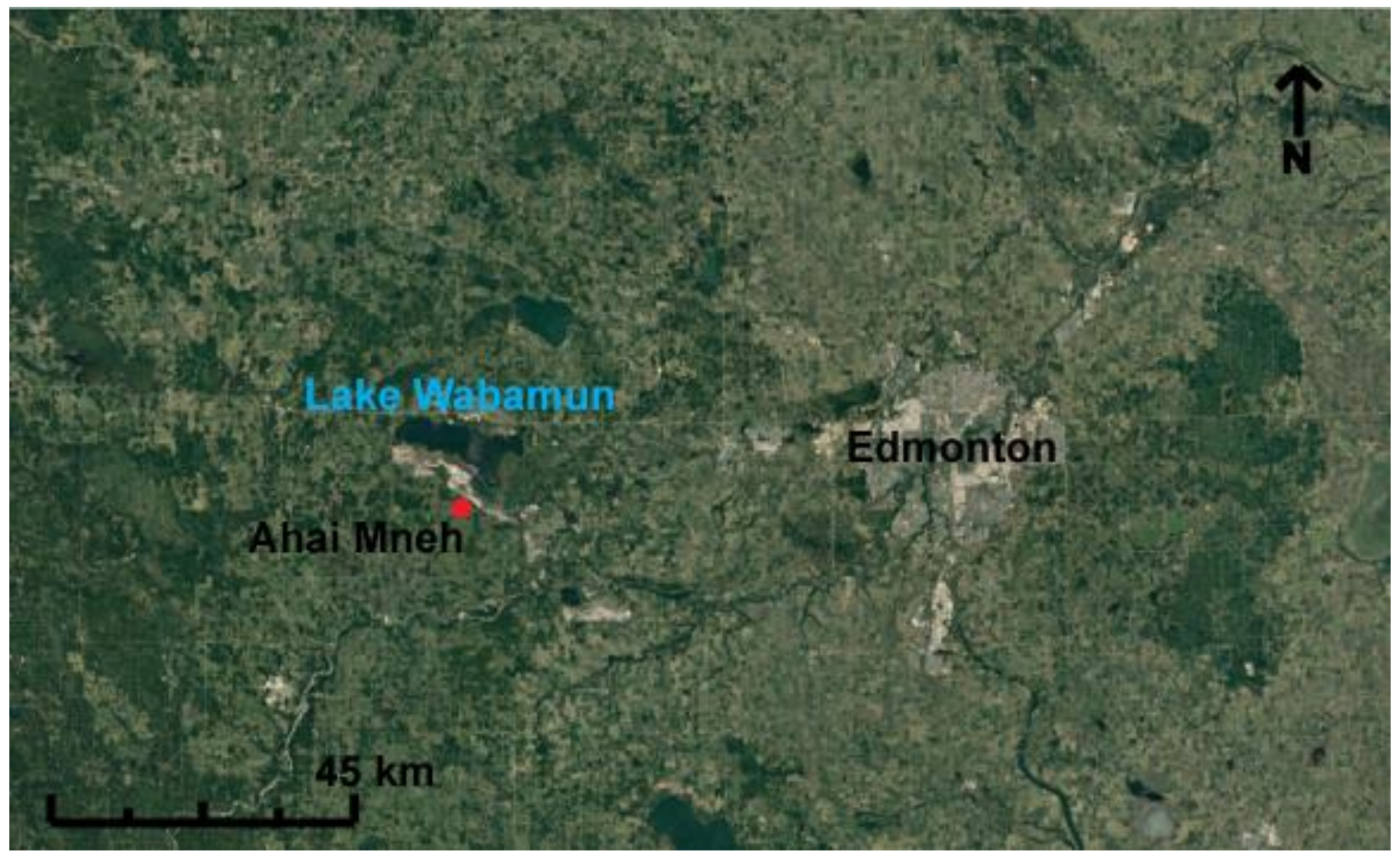

Figure 1. Location of Ahai Mneh (FiPp-33) compared to Edmonton and Lake Wabamun.

Table 1. Identified projectile point styles excavated from Ahai Mneh (FiPp-33) and their associate ages, in radiocarbon years before present (RCYBP). Dates from Bubel, McMurchy, and Lloyd (2012).

\begin{tabular}{|c|c|c|}
\hline Period (age in RCYBP) & $\begin{array}{l}\text { Projectile Point } \\
\text { Style/Complex }\end{array}$ & Age (RCYBP) \\
\hline \multirow{3}{*}{$\begin{array}{l}\text { Early Prehistoric } \\
(11200-7500)\end{array}$} & Agate Basin & $10200-9600$ \\
\hline & Scottsbluff & $9000-8600$ \\
\hline & Lusk & $8300-7500$ \\
\hline \multirow{4}{*}{$\begin{array}{l}\text { Middle Prehistoric } \\
\quad(7500-1350)\end{array}$} & Oxbow & $4500-4100$ \\
\hline & McKean & $4200-3500$ \\
\hline & Hanna & $3900-3500$ \\
\hline & Besant & $2100-1500$ \\
\hline \multirow{2}{*}{$\begin{array}{l}\text { Late Prehistoric } \\
\quad(1350-250)\end{array}$} & Avonlea & $1350-1100$ \\
\hline & $\begin{array}{c}\text { Plains Triangular and } \\
\text { Side-notched arrowheads }\end{array}$ & $1100-250$ \\
\hline
\end{tabular}


Agate Basin Complex and continued periodically through to the Late Prehistoric, just prior to the contact period. Because of the amount of reoccupation and the depth of history, Ahai Mneh is an important part of Alberta's story.

Ahai Mneh was first identified in 1979 during a historical resources impact assessment (HRIA) that consisted only of surface survey (Fedirchuk 1979). In 2005, another HRIA was completed at Ahai Mneh that consisted of surface collections and 46 shovel tests. A total of 120 lithic and bone artifacts were recovered (Soucey et al. 2009:40). Further excavation of Ahai Mneh took place in 2008 as part of a historical resource impact mitigation (HRIM) project at four sites around Lake Wabamun (Soucey et al. 2009:1). Forty-four square metres and an additional 231 shovel tests were excavated, still accounting for a relatively small portion of the overall site. A total of 5798 artifacts were collected including stone tools, lithic debitage, and bone fragments (Soucey et al. 2009:45). Soucey et al.'s (2009:7) analyses of the stone tools suggested that this site had a larger variety of activities occurring at it compared to other precontact sites in the area.

A common problem encountered when interpreting Albertan archaeological sites is compressed stratigraphy. At Ahai Mneh, roughly 10000 years of material culture are compressed into $30-40 \mathrm{~cm}$ thick deposits, which makes it difficult to identify components ${ }^{1}$ and attribute artifacts to a specific time period or occupation. Rawluk et al. (2011) and Schenk and Yanicki (2011) performed analyses on the 2010 field school material from Ahai Mneh in an attempt to account for these issues. Rawluk et al. (2011) performed three-dimensional modeling of the excavated units to see if they could identify

\footnotetext{
${ }^{1}$ A component is a culturally homogeneous stratigraphic unit within a site and corresponds to the number of uses of a site (i.e., a site used once will have a single component, and a site used multiple times will have multiple components) (Darvill 2008).
}

separate components. Their modeling of the three-point proveniences of the lithic artifacts, along with an examination of raw material frequencies, allowed them to tentatively identify two components in one excavation area (Area B) and three components in another (Area A). Schenk and Yanicki (2011) performed an indepth study of the Early Prehistoric projectile points recovered from Ahai Mneh and suggested that there were multiple occupations represented during this time period.

Thorough aggregate analysis has not been completed on any of the Ahai Mneh material to date. The fact that debitage is the most common artifact found at this site calls for a study of this refuse assemblage. I expand on what has previously been learned about Ahai Mneh by analysing the debitage from the two field schools and using the results to learn more about the people using this site.

\section{Review of Debitage Analysis Methods}

Hundreds or thousands of years of taphonomic processes often result in an archaeological assemblage composed of only lithic material (Fig. 2). Of these lithics, debitage by far outnumbers stone tools, sometimes comprising over $99 \%$ of an assemblage (Shott 2004:211). Stone tools were frequently reused or repurposed, and often taken with the owner when they left a site, leaving few for archaeologists to find.

In contrast, flaking debris is often left at or near the location it was made (Binford 1983:153). Stone tools are the "sexy" part of lithic analysis, whereas debitage is often looked at as the necessary evil that must be excavated. Nonetheless, studying flaked debitage informs archaeologists on the acquirement, manufacture, use, and discard of stone tools and debris in the past, which can then inform us of past behaviour (Shott 2004:211-212). 


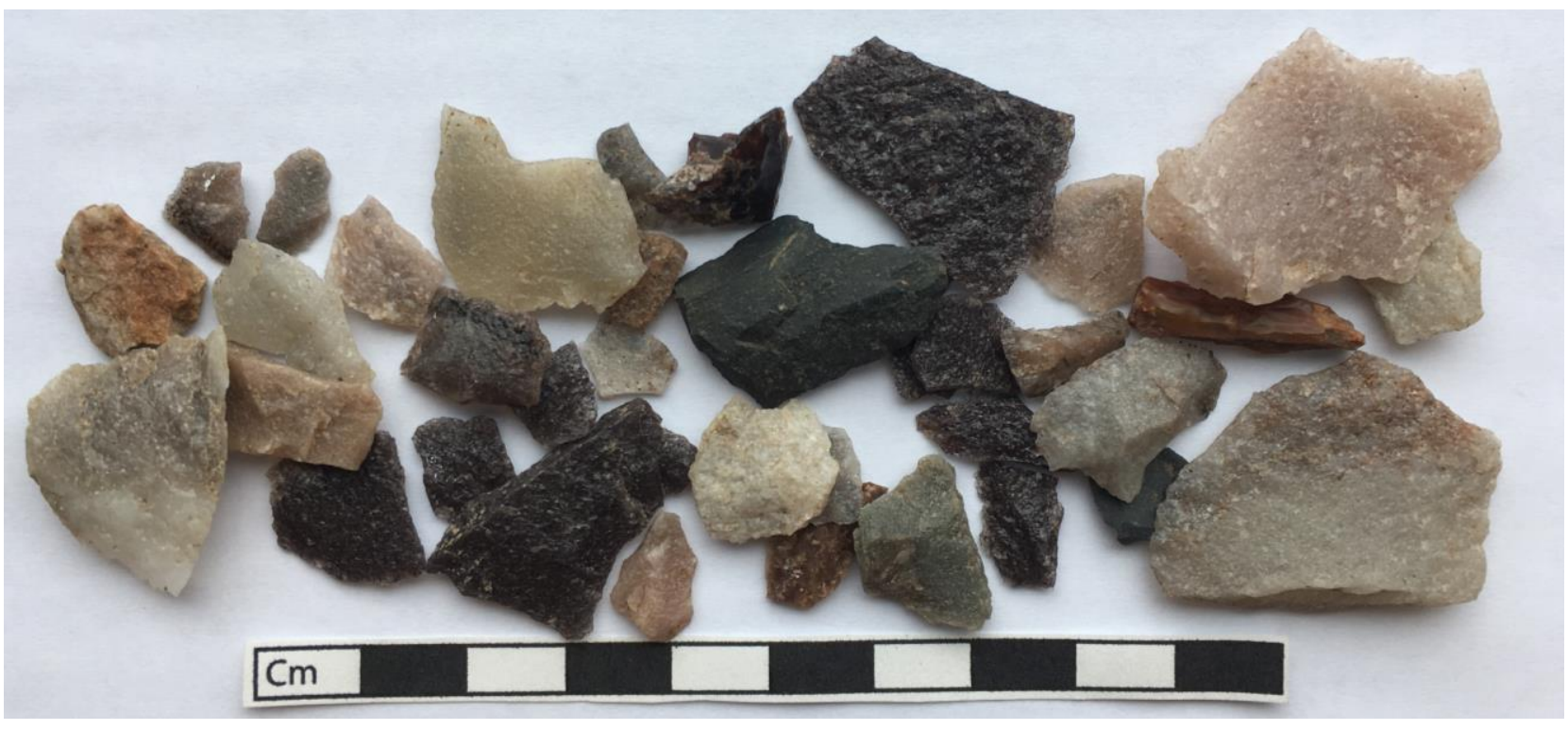

Figure 2. A sample of debitage collected from Ahai Mneh (FiPp-33).

Various approaches to debitage analysis have been developed. Some methods concentrate on individual artifacts while others examine the assemblage as a whole (Andrefsky 2005:113; Odell 2003:120). Individual artifact analysis attempts to identify past behaviour based on a single artifact; for example, the presence of a biface reduction flake suggests that bifaces were manufactured and, likely, used (Andrefsky 2004, 2005). This type of analysis is very time consuming, and can fail to look at the population as a whole. Analysis of the entire assemblage examines the variability within the population to study past behaviour (Andrefsky 2004; 2005). Aggregate analysis studies the assemblage by stratifying the entire assemblage based on characteristics such as size and raw material type and then compares the frequencies in each stratum (Andrefsky 2005:131). Aggregate analysis introduces less bias than other methods, as it makes no assumptions about the type of technology occurring, and is less subject to human differences in identification (Larson 2004). For example, different archaeologists can use different terms for the same artifact, or use different definitions for the various flake types (Bradbury and Carr 2004:86). Using flake attributes that are more difficult to identify also introduces more bias due to the varying lithic expertise and experience of researchers (Bradbury and Carr 2004:86).

Mass analysis is a specific type of aggregate analysis that stratifies the assemblage according to size (Ahler 1989; Carr and Bradbury 2004:21). Mass analysis is a popular method for examining debitage assemblages due to its effectiveness, replicability, and time efficiency (Ahler 1989; Carr and Bradbury 2004:21). The theory behind mass analysis is that flintknapping is a reductive process: no flake can be larger than the core or tool it was produced from (Ahler 1989:89). During the reduction sequence from core to tool "the maximum possible size as well as average size of the flake byproducts should decrease significantly" (Ahler 1989:89). Mass analysis also eliminates intra-observer bias, as it does not assume that any specific technology is occurring (Larson 2004:6). This technique can also be performed without extensive training, as the size of a piece of debitage is simple to identify 
compared to other characteristics. It can even be completed mechanically with nested screens of decreasing size. Researchers can analyse thousands of flakes quite quickly, an obvious advantage that mass analysis has over more individual artifact based analysis (Ahler 1989:8687). This method may be biased by field recovery methods, however; standard practice is to use quarter inch mesh to screen excavated fill, which does not always allow for the collection of small artifacts such as pressure flakes (Carr and Bradbury 2004:42). Another issue with mass analysis is that it can be influenced by taphonomic factors. Trampling and other postdepositional factors can break flakes and increase the number of smaller (broken) flakes, skewing the results. The largest problem, however, is mixed assemblages (Ahler 1989:89; Carr and Bradbury 2004:43; Shott 2004:219), which are discussed further below. Despite these limitations mass analysis continues to be a commonly used method and has "great potential for aiding our understanding of prehistoric lithic assemblages" (Carr and Bradbury 2004:41).

Bradbury and Carr (2004) performed flintknapping experiments to test whether debitage analysis could identify the type of lithic reduction (the process of reducing raw material, such as a core, into something else, such as a tool) occurring. The authors manufactured different cores and tools using various reduction types, including hard and soft hammer percussion, and examined the debitage created from each session (Bradbury and Carr 2004:70). They concluded that assemblages with a large proportion of blocky debris (also known as angular shatter: pieces of debitage with no identifiable flake attributes) are indicative of core reduction, whereas blocky debris was nearly nonexistent, or even completely non-existent, during tool production (Bradbury and Carr 2004:73, 76). They found that core reduction assemblages generally contained $10-20 \%$ angular shatter (Bradbury and Carr 2004:73). This allowed the authors to perform the analyses quickly, making this form of analysis ideal for archaeological studies that are pressured to do more with less time - a common issue in modern archaeology. In particular, the speed with which aggregate and mass analysis can be completed is attractive for CRM companies that may not have the time for complex analyses.

Mixed assemblages still pose a problem for aggregate and mass analyses. These assemblages occur at sites where many activities are occurring (e.g., campsites), including core reduction and different types of tool production. Andrefsky (2005:141) advocates for using aggregate analysis only on assemblages that were deposited from a single distinct event. However, identification of distinct occupation events is not possible at many sites, including Ahai Mneh. Mass analysis cannot determine what types of tools were being produced (Andrefsky 2004:205); however, Bradbury and Carr's (2004:78-81) experiments demonstrated that aggregate analysis could distinguish between core reduction and tool production, even in mixed assemblages.

Andrefsky (2004) is quick to criticize the use of mass analysis for mixed assemblages but he does not suggest an alternative method, other than attempting to delineate individual components. I agree with Andrefsky (2004) that mass analysis cannot be the only form of analysis done on an assemblage, but I disagree that mass analysis cannot be done on mixed assemblages. The sheer volume of debitage from sites like Ahai Mneh requires the use of relatively efficient methods unless researchers want to devote hundreds of hours of time to individual analyses. The compressed nature of sites like Ahai Mneh does not allow for identification of single components, especially when the debitage counts are in the thousands or even millions. Many researchers 


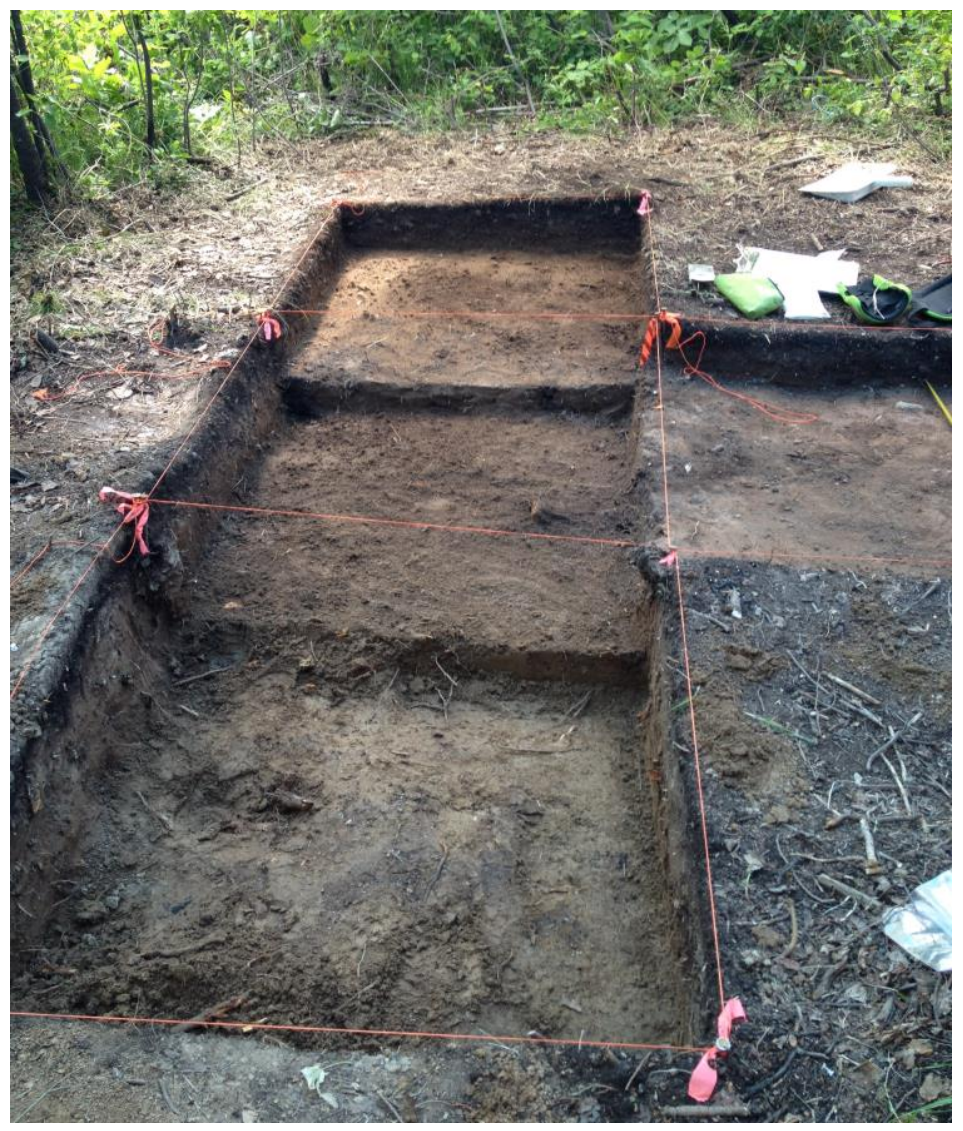

Figure 3. $1 \mathrm{~m} \mathrm{x} 1 \mathrm{~m}$ units in Area A from the 2012 Institute of Prairie Archaeology field school. Looking west.

who continue to use and study debitage analysis see it as a useful way to quickly and simply learn about the assemblage and the site (e.g., Ahler 1989; Bradbury and Carr 2004; Larson 2004; Magne 1989). Bradbury and Carr's (2004) experiments prove that debitage analysis can be successful in mixed assemblages. While aggregate analysis of multi-component sites may introduce error due to the long period of use, I believe it is still a valuable tool to study what was recovered from a site.

\section{Methods}

\section{Excavation and Cataloguing}

During the two field schools a total of $241 \times 1$ metre units were excavated in three different areas (A, B, and C) within Ahai Mneh (fig. 3).
Arbitrary $5 \mathrm{~cm}$ levels were used to control for provenience of screen finds. Three-point proveniences were taken for all artifacts found in situ and the fill was screened through $1 / 4$ inch mesh. Field school students and undergraduate volunteers catalogued the artifacts recovered based on a key provided by the IPA. Each individual artifact was given a unique catalogue number. Cataloguing and storage procedures conform to the Royal Alberta Museum's standards for submission of artifacts.

\section{Debitage Analysis}

Aggregate and mass analyses were chosen because of the large volume of debitage collected from this site. The following categories were analysed: size, raw material, debitage type, amount of cortex, and number of dorsal scars. 
Magne (1989:17) lists dorsal scar count and amount of cortex as two of the most useful variables for reconstructing manufacturing stages of stone tools. The analysis was completed on the assemblage as a whole, but also by $5 \mathrm{~cm}$ level in an attempt to address the issue of mixed assemblages discussed above, and to see if patterns changed through time. Though lithic analysis novices completed the cataloguing and identification, this should minimally affect my analyses because the categories chosen for examination are easily identifiable by beginners.

A total of 8104 lithic artifacts were collected from Ahai Mneh during the two field schools, including 233 stone tools. Surface finds and artifacts recovered from shovel tests were omitted from the analysis because they do not have a secured provenience. As a result, 7709 pieces of debitage with known proveniences are available for this analysis. Angular shatter was not included in the analysis of cortex amount or dorsal scars because, by definition, a dorsal side cannot be identified, leaving 6991 pieces for analysis in these two categories.

\section{Size:}

The debitage was grouped into several size classes $(<3.35 \mathrm{~mm}, 3.35-6.3 \mathrm{~mm}, 6.3-12.5 \mathrm{~mm}$, $12.5-50.0 \mathrm{~mm}$, and $>50.0 \mathrm{~mm}^{2}$ ) based on total length from proximal to distal end. This method does ignore the variability of sizes due to other dimensions such as width and thickness (Andrefsky 2005:102). Because mass analysis can be completed using screens with different sized mesh to quickly divide debitage into these size classes, this can allow long, thin flakes to go through the mesh as long as the width is smaller than the mesh size. Length for this assemblage was measured using a ruler, and length was the size variable chosen because it is the dimension

\footnotetext{
${ }^{2}$ These size classes roughly convert to $1 / 8$ ", $1 / 4 ", 1 / 2$ ", and 2", respectively.
}

commonly measured by researchers, and is the standard measurement with which to complete mass analysis (Andrefsky 2005:132). Length is typically the largest dimension. Logically, larger flakes come from larger pieces of raw material, so are indicative of the earlier stages of reduction, whereas smaller flakes can be indicative of the later stages.

\section{Raw Material:}

The raw material of each artifact was identified during the cataloguing process. Raw material type is a frequent focus of archaeological study as it can inform archaeologists about where people were getting material for making tools. This could also indicate where people travelled to or whom they may have traded with to obtain raw material. Past levels of mobility and raw material preferences can then be examined. I used the frequencies of local versus exotic raw materials to determine the degree of movement the populations using Ahai Mneh exhibited.

\section{Type:}

Each piece of debitage at Ahai Mneh was identified as either a flake or a piece of angular shatter. Bradbury and Carr's (2004) experiments indicated that assemblages with a high proportion of angular shatter are indicative of a focus on core reduction rather than tool production. I use this finding to determine whether core reduction or tool production was a focus at Ahai Mneh.

\section{Amount of Cortex:}

Cortex is the outer surface of a piece of raw material, and can be caused by chemical or mechanical weathering (Andrefsky 2005:103). Cortex is typically highly present in the initial stages of reduction, and is less so in later stages (Magne 1989:17). This follows the logical assumption that the exterior of the raw material 




Figure 4. Results for the mass analysis of the Ahai Mneh (FiPp-33) debitage assemblage.

will be removed first, though the cortex amount will vary due to factors such as the amount of cortex on the original piece, reduction technique, and the type of artifact being produced (Andrefsky 2005:104). I use the amount of cortex present to determine the stages of reduction that were occurring more frequently at Ahai Mneh.

\section{Dorsal Scars:}

Andrefsky (2005:109) demonstrated intraobserver error when counting dorsal scars on flakes and created categories $(0,1,2$, and 3 or more) for analysis that account for this error. The number of dorsal scars increases as reduction continues (Magne 1989:17). I use the frequencies in each of these categories to examine which stages of reduction were occurring.

\section{Results}

\section{Size Classes}

The breakdown of the entire debitage assemblage by size class is shown in Figure 4. The majority of the pieces are less than $12.5 \mathrm{~mm}$ long, and there are few very large $(>50.0 \mathrm{~mm})$ and very small $(<3.35 \mathrm{~mm})$ pieces. The most frequent size class is $6.3-12.5 \mathrm{~mm}$.

\section{Raw Material}

Figure 5 demonstrates the frequency of each raw material from the Ahai Mneh debitage assemblage. Materials with 20 pieces or less are grouped together under the category of "Other" for simplicity and to provide a better visual depiction (see Appendix A for list of raw 


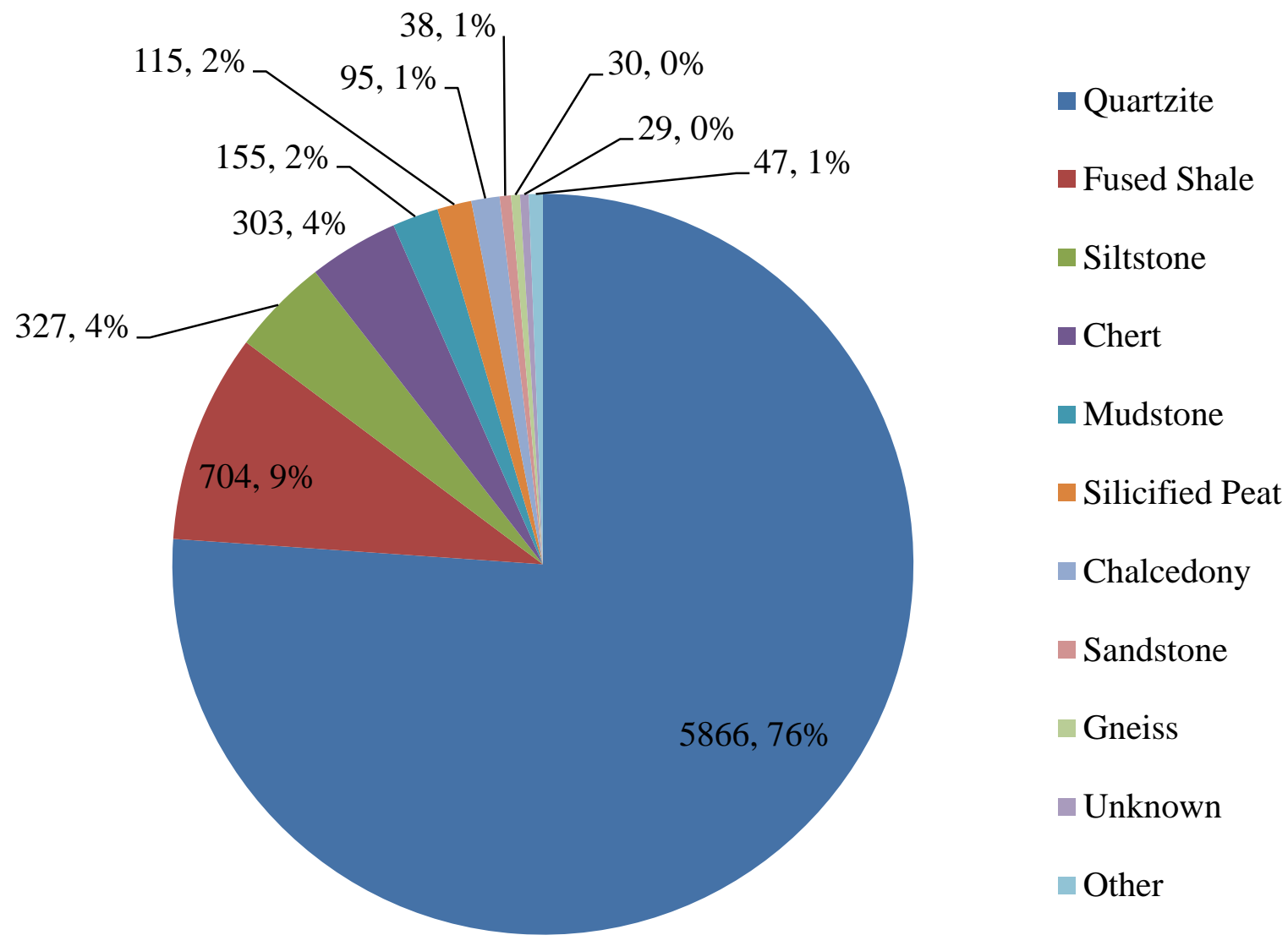

Figure 5. Raw material of the Ahai Mneh (FiPp-33) debitage assemblage.

materials included in "Other"). The assemblage is dominated by quartzite. This material is the most common found at Alberta archaeological sites, and would have been readily accessible as cobbles in the area, such as in creek and riverbeds (Bubel, McMurchy, and Lloyd 2012). The next most frequent raw material, fused shale, is also a local material found in coal seams in the surrounding area $^{3}$. Other common materials, such as types of siltstone, chert, and mudstone, would also be fairly easy to obtain in various places in Alberta (Bubel, McMurchy, and Lloyd 2012). Exotic materials such as obsidian $(\mathrm{N}=9)$ are present, but in low numbers. Another exotic material, Knife River Flint (KRF), has a single

\footnotetext{
${ }^{3}$ The Highvale Coal Mine surrounds Ahai Mneh to the north and east.
}

source in North Dakota and was common in Alberta during the Cody Complex $(9600-8600$ RCYBP) and Besant Phase (2100 - 1500 RCYBP) (Bubel, McMurchy, and Lloyd 2012:31). Despite Ahai Mneh having projectile points dating to these temporal periods, a limited amount of $\mathrm{KRF}$ was recovered $(\mathrm{N}=6)$.

\section{Types of Debitage}

Figure 6 shows the proportion of flakes and angular shatter at Ahai Mneh. Angular shatter comprises only $9.3 \%$ of the Ahai Mneh assemblage. Some of the debitage from Ahai Mneh was identified to different flake types, such as biface reduction flakes and core reduction flakes, but the majority were not because students new to lithic analysis catalogued this assemblage. 


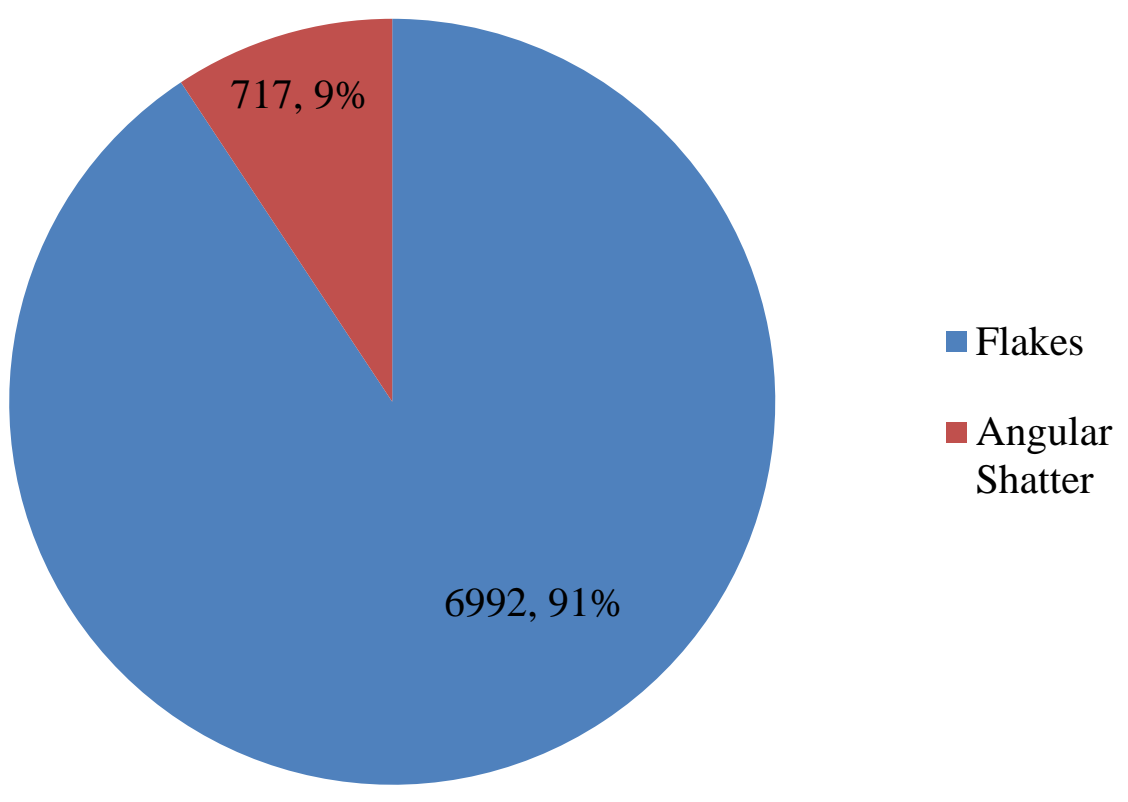

Figure 6: Proportion of flakes versus angular shatter in the Ahai Mneh (FiPp-33) debitage assemblage.

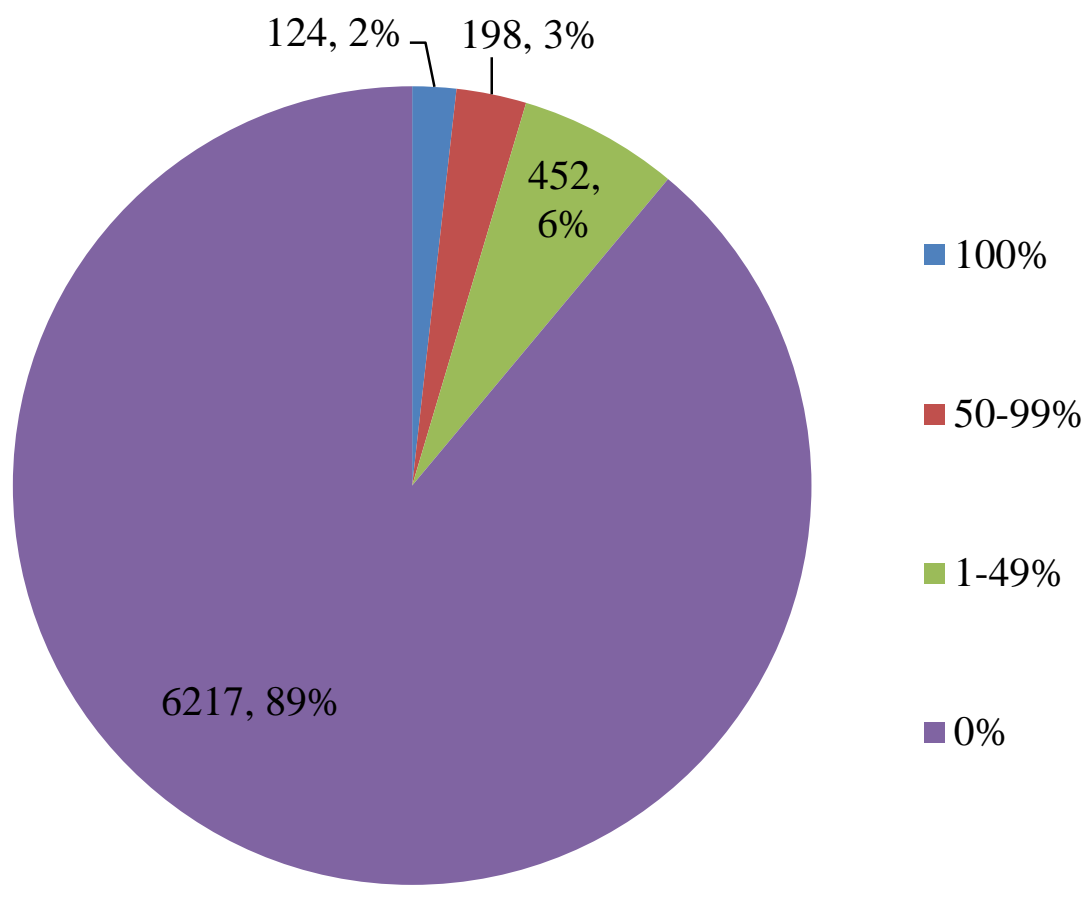

Figure 7: Amount of cortex on flakes from Ahai Mneh (FiPp-33). 


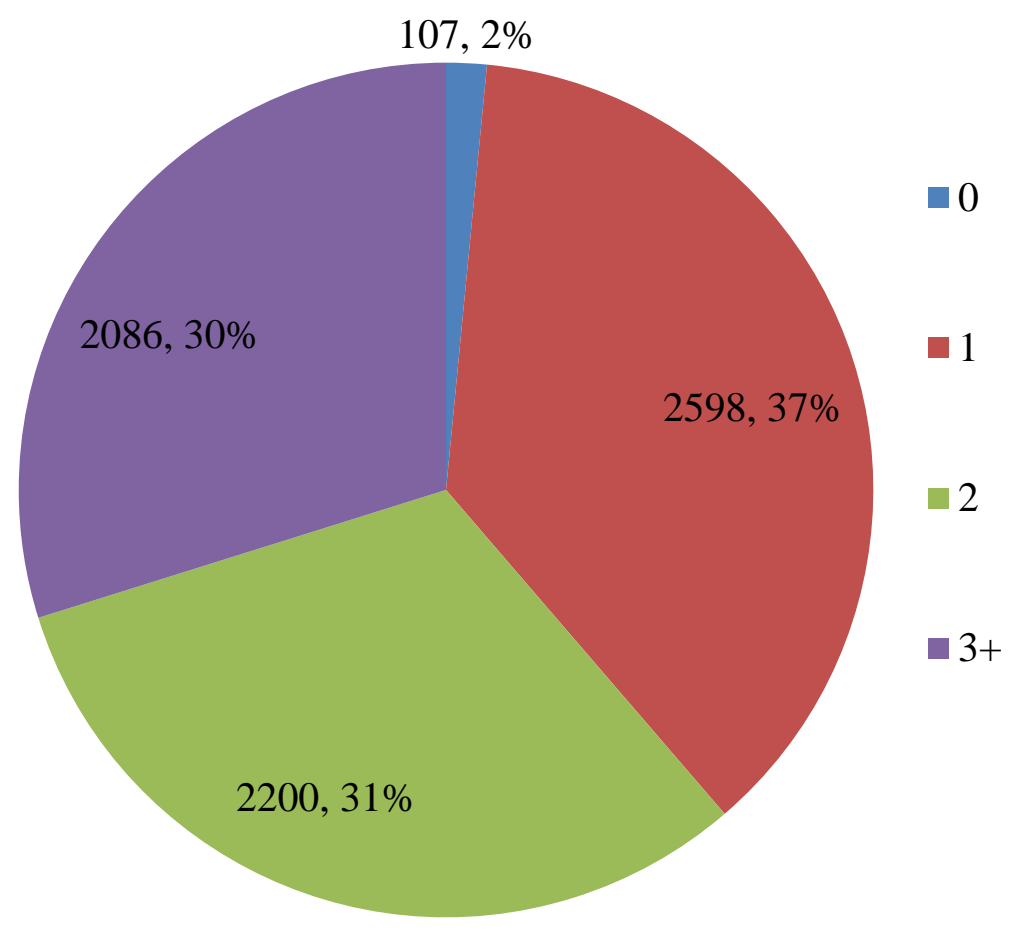

Figure 8. Number of dorsal scars on flakes from the Ahai Mneh (FiPp-33).

These identifications are not included here due to the high probability of incorrect and missed identifications.

\section{Amount of Cortex}

The majority of flakes $(89 \%)$ analyzed at Ahai Mneh did not have any cortex present (fig. 7). The fused shale found at Ahai Mneh is found in outcrops near coal seams and does not have cortex. Removing these pieces from the analysis resulted in a similar $88 \%$ in the zero cortex category.

\section{Dorsal Scars}

Figure 8 depicts the number of dorsal scars on the flakes from Ahai Mneh according to Andrefsky's (2005) categories of $0,1,2$, and 3 or more dorsal scars. Except in the " 0 " category, there is a fairly even spread of flakes with one, two, and three or more dorsal scars (fig. 8).

\section{Analysis by Level}

To mediate the criticisms of using aggregate analysis for mixed assemblages and assemblages that span long time periods, I also examined the categories by level (see Appendix B). Though not a perfect fix, this does decrease the temporal time frame represented, increasing the likelihood that debitage found at the same level were produced at the same time. I examined the debitage collected from each $5 \mathrm{~cm}$ level, and my analysis produced the same results as above, which strengthens their validity. The compressed nature of this site does not allow for extremely precise single-component based analyses, but the level based analyses are still useful in analysing temporal trends.

\section{Discussion}

The size of the Ahai Mneh debitage was the first characteristic examined. Size can be an indicator 
of the reduction stage, as pieces tend to get smaller as reduction progresses (Ahler 1989:89). Debitage size is also an indicator of the size of raw material available at the site. The small number of large flakes suggests that the raw materials being brought to the site were not large to begin with. Given that the majority of the assemblage is quartzite, this is consistent with people collecting river cobbles for use. Also, if people were focusing on tool production, they may have prepared cores elsewhere and transported them to Ahai Mneh as smaller pieces. Another reason that large pieces of debitage are not found could be that raw material was utilized to its full extent; large flakes could be turned into tools, creating smaller flakes and leaving no unused larger flakes. However, provided that the majority of the raw material was locally obtained, utilizing all available raw material pieces would be unnecessary. The few cores $(\mathrm{N}=15)$ that were excavated at this site are not large (majority are less than 500 grams), suggesting that few cores were brought to the site, cores were being highly utilized, cores were being transported away from the site, or a combination of these scenarios.

The results of the raw material analysis demonstrate a heavy reliance on local raw materials at Ahai Mneh, and supports the argument that trade for raw materials was not a focus while groups were occupying the site. Less than $1 \%$ of the lithic artifacts recovered from Ahai Mneh would be considered exotic. Since exotic materials such as obsidian and KRF do appear in higher frequencies at other Albertan sites throughout various time periods, I suggest that Ahai Mneh residents were not travelling or trading for these materials to the extent that other groups in the province were. Another possibility is that Ahai Mneh was occupied during periods of the year when trade or travel was not available. Instead, raw material seems to have been collected very near to the site, and may have been the reason for continuous reoccupation of Ahai Mneh.

Bradbury and Carr (2004:73) found that experimental assemblages had between 10-20\% angular shatter. Angular shatter comprises less than $10 \%$ of the Ahai Mneh assemblage (9.3\%), indicating that tool production was the focus, but that a minimal amount of core reduction did occur. Soucey et al. (2009) corroborate these findings as their debitage assemblage included only $11.4 \%$ angular shatter.

Most of the flakes from Ahai Mneh did not have cortex on them, suggesting that the later stages of reduction were occurring on site. As mentioned earlier, fused shale does not have cortex. The other raw materials found at the site, most notably quartzite, but also siltstone and chert, do typically have cortex. Magne (1989:1718) states that after the initial reduction stages the amount of cortex should decrease sharply. The large quantity of flakes without cortex at Ahai Mneh (89\%) indicates that the primary reduction stages, where cortex would be removed, occurred elsewhere. People were likely bringing in prepared cores, perhaps in the form of bifaces, and then completing final tool production at Ahai Mneh. Another explanation is that individuals were revitalizing used tools. For example, retipping broken projectile points for further use would produce flakes with no cortex.

The results from the analysis of dorsal scars are consistent with a focus on tool production, with core reduction occurring off site. If core reduction were more frequent, we would expect more flakes with zero or one dorsal scar. The number of dorsal scars increases as reduction progresses (Magne 1989:17). The dorsal side of flakes with zero dorsal scars are completely covered in cortex, and would be from the primary reduction stage. Only $2 \%$ of the flakes have zero dorsal scars (similarly, only $2 \%$ of the flakes have $100 \%$ cortex). Cortex may or may not be present 
on flakes with one dorsal scar, but these are more likely to be produced during the initial stages of reduction.

Overall, the results of the debitage analyses at Ahai Mneh support the interpretation that this was a campsite where people frequently made and rejuvenated tools. The results demonstrate a focus through time on tool production using raw materials that had been prepared off site. Local materials were obtained nearby and provided the bulk of resources. The later stages of the reduction sequence occurred more often, although all stages occurred in varying frequencies. The infrequency of cores, angular shatter, large flakes, and cortical flakes at Ahai Mneh suggest that people were bringing prepared cores or raw material to the site from another location. There were various ways for people to transport raw material more efficiently than carrying whole cores, including prepared cores, flake and biface blanks, and preforms (Pecora 2001). My analyses indicate that the majority of raw material transported to Ahai Mneh was done so in one of these forms. It would have been much more efficient to complete the initial reduction at the source rather than have to carry full cores to Ahai Mneh or other sites. In conjunction my analyses indicate that prepared cores or more formed tools (preforms) were brought to the site and that the later stages of production occurred at Ahai Mneh.

Ahai Mneh was utilized for thousands of years in what appears to be a similar way. Throughout time, people were bringing in previously processed raw materials rather than full cores. This site was evidently a good place for a campsite. The highest part of the site provides excellent visibility of the landscape for hunting or scouting. It is also near a large water source, Lake Wabamun, which has been present continually from the time the site was first occupied until the present (Hickman, Schweger, and Habgood 1984). Lake Wabamun did not dry up during the Hypsithermal (a warm, dry period during the middle Holocene), and therefore may have provided an oasis of sorts during this time. The North Saskatchewan River, a source of raw material and an avenue for transport, is less than $15 \mathrm{~km}$ southeast. If people were occupying Ahai Mneh for long periods of time they would need to replenish their raw material sources. Retooling would have been easily accomplished by acquiring local materials from rivers (quartzite) or nearby coal seams (fused shale) and bringing resources back as prepared materials. The landscape around Ahai Mneh was more suitable for setting up a large camp rather than areas right by the river or near the coal seams. Resource collection implies knowledge of the area and the available raw materials. I would argue that the consistent re-use of this site indicates knowledge of the local raw materials, and this access may have been one reason for continued use. Beck et al. (2002) indicated that the farther people had to travel, the more reduction occurred at a quarry. This suggests that the people occupying Ahai Mneh were mobile and potentially used this site as a base to retool with quartzite and fused shale before moving on.

Archaeological sites in Alberta so often yield only lithic material. Except for small, unidentifiable pieces of decomposed bone, most of the assemblage recovered at Ahai Mneh is lithic, and of that roughly ninety-five percent is debitage. Stone tool analysis is useful in identifying what tools are present at a site, and the tools can be used to indicate what activities took place (i.e., an endscraper suggests hide working took place). However, where a tool is discarded is not necessarily where it was used. Broken and reusable artifacts can be kept to be recycled or repaired instead of discarded (e.g., Binford 1976). A site where hide working occurred may show no evidence of it if all the tools were reused or recycled. Multiple cultural 
processes play into whether a stone tool will be discarded, including curation rates, breakage rates, size, manufacturing cost, transportation costs, and more (Adams 2003; Schiffer 1987; Shott 1989; Surovell 2009). Conversely, debitage is unique in that it is typically discarded at or very near its origin and then left in situ, with minimal cultural processes applied to it (Ahler 1989:86; Binford 1983:153; Schiffer 1987:267; Stevenson 1991). In this sense, debitage analysis can provide a way to study past activities without as much human intervention in discard and post-discard processes. Since such a large portion of the artifact assemblage at Ahai Mneh is debitage, debitage analysis is one of the few ways with which we can learn more about the past use of this site and the activities that occurred there. Examining the Ahai Mneh debitage collection as a whole and by level resulted in the identification of tool production as a main activity at this site, which could not be confirmed prior to this analysis.

I argue that debitage analysis should be a method applied to the many sites in Alberta and the rest of North America where lithic debitage is the main artifact collected. In particular, my analysis did not require large amounts of time, which is ideally suited for CRM or recoverybased archaeology. The most time consuming part of my analysis was the cataloguing and identifying of each artifact. However, many of these methods can be applied without individual cataloguing. For example, size can be examined with nested screens. As discussed previously, this method of size division does not keep a consistent dimension. My method of using length was more time consuming, since each flake was placed into a size category individually, but I argue this method is more consistent, and can still be done quite quickly if needed. Debitage can also be quickly sorted based on other characteristics, like amount of cortex, without individual cataloguing.
Aggregate debitage analysis is a technique that has the potential to be very useful for CRM archaeologists who do not have the time to do complex analyses, but do have time for simple debitage analyses to provide some initial conclusions. It will also be relatively easy to apply these methods to any collections that have already been catalogued, provided that the characteristics used were noted. The analysis does not require much training, as the characteristics noted are quantitative and can be easily replicated. This methodology is ideal for field school collections and CRM collections where the researchers may not be lithic or stone tool experts.

\section{Conclusion}

The analysis of the Ahai Mneh debitage assemblage concluded that tool production and rejuvenation were the main lithic activities occurring throughout time. Prior to the above analyses, it was evident that abundant flintknapping had occurred, but not for what exact purpose. From my analysis we now know that local material was relied on and that people were bringing prepared raw material to the site rather than complete cores. The initial stages of reduction were occurring elsewhere, with only the final reduction stages occurring at Ahai Mneh. The availability of raw material, along with the proximity of Lake Wabamun and the North Saskatchewan River, was likely a reason for the continued use of Ahai Mneh. The completed debitage analysis adds to the knowledge of the site's history and indicates past land use and activity. Much more can and should be done not only with the above results, but also by applying more and other methods to the collection. Using multiple methods of analysis will provide a more holistic interpretation of site activities (Carr and Bradbury 2004; Larson 2004; Shott 2004). The stone tools from Ahai Mneh should be analysed 
and compared to this analysis, and the flakes should be individually analysed and identified to different types. It would also be fruitful to examine the debitage by excavation area, and include the previous CRM excavations in the analysis. This may reveal differences in activity among the areas. Learning everything possible about a site furthers our knowledge of Alberta's rich history, and also helps to protect significant sites from further destruction by identifying these key sites.

\section{Acknowledgements}

This paper is a reworked version of a term paper submitted to Todd Kristensen for his Stone Tools course in Winter 2015, and I thank him for earlier comments. Thank you to Dr. John (Jack) Ives, instructor of both 2010 and 2012 field schools, for his guidance. I also thank my fellow field school students and IPA volunteers for their work excavating and cataloguing this assemblage. Three anonymous reviewers provided valuable feedback and suggestions that greatly improved this paper.

\section{References Cited}

Adams, William Hampton. 2003. Dating Historical Sites: The Importance of Understanding Time Lag in the Acquisition, Curation, Use, and Disposal of Artifacts. Historical Archaeology 37(2):38-64.

Ahler, Stanley A. 1989. Mass Analysis of Flaking Debris: Studying the Forest Rather Than the Tree. In Alternative Approaches to Lithic Analysis. D. O. Henry and G. H. Odell, eds. Pp. 85-118. Archaeological Papers of the American Anthropological Association No. 1. Washington, D.C.

Andrefsky, William Jr. 2004. Partitioning the Aggregate: Mass Analysis and Debitage Assemblages. In Aggregate Analysis in Chipped Stone. Christopher T. Hall and Mary Lou Larson, eds. Pp. 201-210. Salt Lake City: The University of Utah Press.

2005. Lithics: Macroscopic Approaches to Analysis, $2^{\text {nd }}$ edition. New York: Cambridge University Press.

Beck, Charlotte, Amanda K. Taylor, George T. Jones, Cynthia M. Fadem, Caitlyn R. Cook, and Sarah A. Millward. 2002. Rocks are heavy: transport costs and Paleoarchaic quarry behaviour in the Great Basin. Journal of Anthropological Archaeology 21(4):481-507.
Binford, Lewis R. 1976. Forty-Seven Trips: A Case Study in the Character of Some Formation Processes of the Archaeological Record. In Contributions to Anthropology: The Interior Peoples of Northern Alaska. Edwin S. Hall Jr., ed. Pp. 299-351. Archaeological Survey of Canada, Paper No. 49.

1983. In Pursuit of the Past: Decoding the Archaeological Record. New York: Thames and Hudson.

Bradbury, Andrew P. and Philip J. Carr. 2004. Combining Aggregate and Individual Methods of Flake Debris Analysis: Aggregate Trend Analysis. North American Archaeologist 25(1):65-90.

Bubel, Shawn, James McMurchy, and Duncan Lloyd. 2012. Record in Stone: Familiar Projectile Points from Alberta. Lethbridge, Alberta: Archaeological Society of Alberta: Lethbridge Centre.

Carr, Philip J., and Andrew P. Bradbury. 2004. Exploring Mass Analysis, Screen, and Attributes. In Aggregate Analysis in Chipped Stone. Christopher T. Hall and Mary Lou Larson, eds. Pp. 21-44. Salt Lake City: The University of Utah Press.

Darvill, Timothy. 2008. The Concise Oxford Dictionary of Archaeology. Oxford: Oxford University Press.

Fedirchuk, Gloria. 1979. FiPp-33 Archaeology Site Inventory Form. On file with the Archaeology Survey of Alberta, Edmonton.

Hickman, M., C. E. Schweger and T. Habgood. 1984. Lake Wabamun, Alta.: a paleoenvironmental study. Canadian Journal of Botany 62(7): 1438-1465

Larson, Mary Lou. 2004. Chipped Stone Aggregate Analysis in Archaeology. In Aggregate Analysis in Chipped Stone. Christopher T. Hall and Mary Lou Larson, eds. Pp. 3-17. Salt Lake City: The University of Utah Press.

Magne, Martin P.R. 1989. Lithic Reduction Stages and Assemblage Formation Processes. In Experiments in Lithic Technology. Daniel S. Amick and Raymond P. Mauldin, eds. Pp. 15-31. Oxford: BAR International Series 528.

Odell, George H. 2003. Lithic Analysis. Manuals in Archaeological Method, Theory, and Technique. New York: Springer Science + Business Media.

Pecora, Albert M. 2001. Chipped Stone Tool Production Strategies and Lithic Debris Patterns. In Lithic Analysis: Context, Form, Meaning. William Andrefsky Jr., eds. Pp. 173-190. Salt Lake City: The University of Utah Press.

Rawluk, Matt, Aileen Reilly, Jo-Anne Schenk, Peter Stewart, and Gabriel Yanicki. 2011. Identification of a Paleoindian Occupation in Compressed Stratigraphy: A Case Study from Ahai Mneh (FiPp-33). Diversipede 1(1):1-15.

Schenk, Jo-Anne and Gabriel Yanicki. 2011. Early Prehistoric Sites in Alberta and How They Relate to Ahai Mneh (FiPp-33). Diversipede 1(1):35-41. 
Schiffer, Michael B. 1987. Formation Processes of the Archaeological Record. Albuquerque: University of New Mexico Press.

Shott, Michael J. 1989. On Tool-Class Use Lives and the Formation of Archaeological Assemblages. American Antiquity 54(1):9-30.

2004. Aggregate Methods and the Future of Debris Analysis. Aggregate Analysis in Chipped Stone. Christopher T. Hall and Mary Lou Larson, eds. Pp. 317. Salt Lake City: The University of Utah Press.
Soucey, Kristen, Bruce F. Ball, and Loic Bosher. 2009. "Historical Resource Impact Mitigation. FiPp-33, FjPp50, FjPq-36, and FjPq-37. TransAlta Generation Partnership. Highvale Mine Pits 3, 4, and 5 Expansion," 2 volumes. ASA Permit 2008-320. Report on file, Archaeological Survey of Alberta, Edmonton.

Stevenson, Marc G. 1991. Beyond the Formation of HearthAssociated Artifact Assemblages. In The Interpretation of Archaeological Spatial Patterning. Ellen M Kroll and T. Douglas Price, eds. Pp. 269-299. New York: Plenum Press.

Surovell, Todd. 2009. Toward a Behavioral Ecology of Lithic Technology: Cases From Paleoindian Archaeology. Tucson: University of Arizona Press.

Appendix A: Raw material analysis.

Table A.1. Raw material counts and percentages included in the "Other" category from Ahai Mneh.

\begin{tabular}{|c|c|c|}
\hline Raw Material & Count & Percentage \\
\hline Quartz & 13 & 0.17 \\
\hline Granite & 11 & 0.14 \\
\hline Obsidian & 9 & 0.12 \\
\hline Knife River Flint & 6 & 0.08 \\
\hline Petrified Wood & 5 & 0.06 \\
\hline Argillite & 1 & 0.01 \\
\hline Basalt & 1 & 0.01 \\
\hline Dacite & 1 & 0.01 \\
\hline
\end{tabular}

Appendix B: Debitage analysis by level at Ahai Mneh.

Table B.1. Debitage types distributed by level.

\begin{tabular}{|c|c|c|c|c|c|c|c|c|c|c|c|}
\hline \multirow{2}{*}{ Level } & \multicolumn{9}{|c|}{ Type } & \multirow{2}{*}{ Total } \\
\cline { 2 - 12 } & $\mathbf{1}$ & $\mathbf{2}$ & $\mathbf{3}$ & $\mathbf{4}$ & $\mathbf{5}$ & $\mathbf{6}$ & $\mathbf{7}$ & $\mathbf{8}$ & $\mathbf{9}$ & \\
\hline $\mathbf{1}$ & 171 & 65 & 9 & 3 & 45 & 11 & 1 & 0 & 13 & $\mathbf{3 1 8}$ \\
\hline $\mathbf{2}$ & 1072 & 500 & 41 & 97 & 328 & 91 & 1 & 0 & 128 & $\mathbf{2 2 5 8}$ \\
\hline $\mathbf{3}$ & 1286 & 510 & 83 & 58 & 354 & 95 & 2 & 3 & 273 & $\mathbf{2 6 6 4}$ \\
\hline $\mathbf{4}$ & 721 & 296 & 49 & 40 & 77 & 47 & 1 & 3 & 188 & $\mathbf{1 4 2 2}$ \\
\hline $\mathbf{5}$ & 395 & 105 & 24 & 18 & 36 & 32 & 1 & 0 & 82 & $\mathbf{6 9 3}$ \\
\hline $\mathbf{6}$ & 126 & 46 & 8 & 4 & 7 & 13 & 0 & 0 & 24 & $\mathbf{2 2 8}$ \\
\hline $\mathbf{7}$ & 43 & 16 & 1 & 1 & 1 & & 1 & 0 & 3 & $\mathbf{6 6}$ \\
\hline $\mathbf{8}$ & 3 & 3 & 0 & 0 & 0 & 0 & 0 & 0 & 2 & $\mathbf{8}$ \\
\hline Other & 33 & 10 & 2 & 0 & 0 & 3 & 0 & 0 & 4 & $\mathbf{5 2}$ \\
\hline Total & $\mathbf{3 8 5 0}$ & $\mathbf{1 5 5 1}$ & $\mathbf{2 1 7}$ & $\mathbf{2 2 1}$ & $\mathbf{8 4 8}$ & $\mathbf{2 9 2}$ & $\mathbf{7}$ & $\mathbf{6}$ & $\mathbf{7 1 7}$ & $\mathbf{7 7 0 9}$ \\
\hline
\end{tabular}

4 "Other" indicates debitage that was not assigned to a specific level, including artifacts that fell from walls or were not properly provenienced. 
Hallson Debitage Analysis at Ahai Mneh

Table B.2. Debitage size classes distributed by level.

\begin{tabular}{|c|c|c|c|c|c|c|}
\hline \multirow{2}{*}{ Level } & \multicolumn{5}{|c|}{ Size Class } & \multirow{2}{*}{ Total } \\
\cline { 2 - 6 } & $\mathbf{1}$ & $\mathbf{2}$ & $\mathbf{3}$ & $\mathbf{4}$ & $\mathbf{5}$ & $\mathbf{3 1 8}$ \\
\hline $\mathbf{1}$ & 73 & 56 & 115 & 73 & 1 & $\mathbf{2 2 5 8}$ \\
\hline $\mathbf{3}$ & 122 & 491 & 1068 & 569 & 8 & $\mathbf{2 6 6 4}$ \\
\hline $\mathbf{4}$ & 48 & 463 & 1350 & 791 & 12 & $\mathbf{1 4 2 2}$ \\
\hline $\mathbf{5}$ & 22 & 173 & 718 & 502 & 7 & $\mathbf{6 9 3}$ \\
\hline $\mathbf{6}$ & 36 & 70 & 327 & 256 & 4 & $\mathbf{2 2 8}$ \\
\hline $\mathbf{7}$ & 4 & 21 & 99 & 104 & 0 & $\mathbf{6 6}$ \\
\hline $\mathbf{8}$ & 1 & 8 & 41 & 16 & 0 & $\mathbf{8}$ \\
\hline Other & 0 & 0 & 7 & 1 & 0 & $\mathbf{5 2}$ \\
\hline Total & $\mathbf{3 0 6}$ & $\mathbf{1 2 8 7}$ & $\mathbf{3 7 5 8}$ & $\mathbf{2 3 2 6}$ & $\mathbf{3 2}$ & $\mathbf{7 7 0 9}$ \\
\hline
\end{tabular}

Table B.3. Debitage cortex amount classes distributed by level.

\begin{tabular}{|c|c|c|c|c|c|}
\hline \multirow{2}{*}{ Level } & \multicolumn{4}{|c|}{ Amount of Cortex } & \multirow{2}{*}{ Total } \\
\hline & $\mathbf{0}$ & 1 & 2 & 3 & \\
\hline 1 & 4 & 10 & 21 & 270 & 305 \\
\hline 2 & 31 & 45 & 147 & 1907 & 2130 \\
\hline 3 & 53 & 69 & 165 & 2104 & 2391 \\
\hline 4 & 18 & 45 & 63 & 1107 & 1233 \\
\hline 5 & 10 & 21 & 40 & 540 & 611 \\
\hline 6 & 7 & 5 & 13 & 179 & 204 \\
\hline 7 & 1 & 0 & 2 & 59 & 62 \\
\hline 8 & 0 & 0 & 0 & 7 & 7 \\
\hline Other & 0 & 3 & 1 & 44 & 48 \\
\hline Total & 124 & 198 & 452 & 6217 & 6991 \\
\hline
\end{tabular}

Table B.4. Debitage dorsal scar classes distributed by level.

\begin{tabular}{|c|c|c|c|c|c|}
\hline \multirow{2}{*}{ Level } & \multicolumn{4}{|c|}{ Dorsal Scars } & \multirow{2}{*}{ Total } \\
\hline & $\mathbf{0}$ & 1 & 2 & $3+$ & \\
\hline 1 & 3 & 160 & 74 & 68 & 305 \\
\hline 2 & 24 & 817 & 705 & 584 & 2130 \\
\hline 3 & 46 & 900 & 738 & 707 & 2391 \\
\hline 4 & 16 & 421 & 394 & 402 & 1233 \\
\hline 5 & 10 & 196 & 193 & 212 & 611 \\
\hline 6 & 7 & 62 & 56 & 79 & 204 \\
\hline 7 & 1 & 23 & 21 & 17 & 62 \\
\hline 8 & 0 & 3 & 2 & 2 & 7 \\
\hline Other & 0 & 16 & 17 & 15 & 48 \\
\hline Total & 107 & 2598 & 2200 & 2086 & 6991 \\
\hline
\end{tabular}

